\title{
PERCEPTUAL ENABLERS OF GLOBAL NASCENT ENTREPRENEURS: A QUANTITATIVE INVESTIGATION BASED ON GLOBAL ENTREPRENEURSHIP MONITOR DATA
}

\author{
Shuai Qin \\ Aston Business School, Centre for Research in Ethnic Minority Entrepreneurship, Aston University, \\ Birmingham, UK \\ Email: 190229083@aston.ac.uk
}

Received: 7 May 2021. Revision received: 3 Jun 2021. Accepted: 19 June 2021

\begin{abstract}
With the deepening of research on entrepreneurial activity motivation, academic discourse has been cognizant of the incompleteness of macro-contextual factors and micro-personality in explaining entrepreneurship momentum. The interaction mechanism between context and potential nascent entrepreneurs has gradually become a theoretical hot spot in the $21 \mathrm{st}$ century. This article aims to elaborate on the emerging debate about perceptual factors of entrepreneurship and identify salient perceptual enablers of entrepreneurial activities for global nascent entrepreneurs. In order to bring empirical breakthroughs to the table, this article employs nascent entrepreneurial activity data of more than 50 countries from 2011 to 2019 gathered by Global Entrepreneurship Monitor (GEM). The author built a pooled cross-sectional dataset to unveil the perceptual determinants shared by new entrepreneurs worldwide and employed pooled OLS regression. The study confirms the significant positive influence of the 'perceived opportunity' (PO), 'perceived capability' (PC), and 'immersion in entrepreneurial culture/social norm' (CSN) and negative influence of 'fear of failure' (FF) on national entrepreneurial activity. This empirical article is a prompt exploration of entrepreneurial enablers. Among the existing empirical milestones, few attempts mentioned shared perceptual needs among entrepreneurs on various continents. This paper introduces an emerging cross-national variable structure grounded on existing conceptual elements. It contributes to corresponding knowledge by updating the time span/contextual background, expands the scope of theory applicability, and recommends an inclusive environment practically. When reflecting on the entrepreneurship context and policies, this research can serve as a priori insights for evaluating entrepreneurial support and proffer 'perceptual criteria' for comparison between cross-national policies.
\end{abstract}

KEYWORDS: nascent entrepreneurs, entrepreneurial activity, perceptual enablers, global pattern, pooled cross-sectional data

JEL CLASSIFICATION: L26, D91, O50, Z10, M50.

Reference: Qin, S. (2021). Perceptual Enablers Of Global Nascent Entrepreneurs: A Quantitative Investigation Based On Global Entrepreneurship Monitor Data. International Journal of Entrepreneurial Knowledge, 9(1), 112-126. doi: 10.37335/ijek.v9i1.132

\section{INTRODUCTION}

Theorists and practitioners have corroborated the significance of entrepreneurship for national economic revitalization and mobilization in multiple regional contexts (Sergi et al., 2019). Entrepreneurship effectuates industrial innovation, improves employment structure and empowers nationals to respond to changing context (Mohammadali \& Abdulkhaliq, 2019). The exploration of determinants for entrepreneurial activity also turns to full swing. Entrepreneurship intention (EI) theory is an emerging branch of entrepreneurial literature (Khursheed et al., 2018), and it is often used to inform entrepreneurial activity (action). The theoretical constructs for EI are numerous. For instance, the push-pull mechanism (Ojiaku et al., 2018), personality traits (Munir et al., 2019), social norm and value proposition (Fernandes et al., 2020), role model (Wannamakok \& Chang, 2020), macroeconomic and policy interventions (Bras, 2020) have been proposed one after another. However, potential entrepreneurs are embedded in the entrepreneurial context, which means that the interaction between micro traits and context is complex and inevitable (Amini Sedeh et al., 2020). Therefore, to explain this complex interaction mechanism, 


\section{INTERNATIONAL JOURNAL OF ENTREPRENEURIAL KNOWLEDGE}

Issue 1, volume 9, ISSN 2336-2960 (Online)

www.ijek.org

perceptual factors have become imperative indicators that map entrepreneurs' reaction within the macrocontext (Barrera Verdugo, 2020).

However, in most EI literature, the inspection and exploration of perceptual enablers are still bewildering. In particular, there are still three main theoretical/methodological gaps that have not yet been resolved, highlighting the necessity of this article:

- The existing entrepreneurial literature still lacks typological diversity in the discussion of perceptual enablers. The current mainstream empirical designs include: exploring the relationship between the perceptual factors of entrepreneurs and EI in a single country (Tunali \& Sener, 2019), and exploring the perceptual factors in regions with high geopolitical/economic similarities (Dileo \& Losurdo, 2016; Brás, 2020; Vodă et al., 2020).

- The time-lag data used in existing empirical studies, restricting the theoretical value of informing emerging policy. For entrepreneurs embedded in context, the interaction between their micropersonality and context cannot be defaulted to be constant (Amini Sedeh et al., 2020). For example, the introduction of international crisis data may distort the model in a risk aversion manner.

- Perceptual factors are typically prominent as independent variables in many EI literature. However, Bogatyreva et al. (2019) pointed out that there is still an implicit gap between EI and entrepreneurship activity (EA) theoretically. For example, in their articles, Hofstede cultural dimensions contribute to the transformative process.

Therefore, the limited scale in data, timeliness of results and applicability of the EI factor in the EA decision mechanism still call for more methodological and empirical contributions.

In practice, the entrepreneurial performance between countries has also diverged with contexts and heterogeneous institutional characteristics (Acs et al., 2018). Concerning the modern entrepreneurial paradigm under the accelerating internationalisation, emerging born global entrepreneurship also highlight the importance of inclusive contexts for foreign entrepreneurs (Morozova et al., 2019). Secondly, the influx of economic migrants and displaced people also drives the flow of entrepreneurship between continents. In the 21 st century, economic migrants and refugees frequently travel for livelihood/survival, which causes most immigrants who land in a hurry to face barriers in the host labour market (policy, structure, and market demand) (Ram et al., 2017). Pursuing self-employment has served as a pivoting way for these diaspora communities to achieve self-reliance (Barberis \& Solano, 2018).

In the emerging international economic panorama, institutional adaptability and structural measures are essential to support entrepreneurship to promote regional economic development (Morozova, 2019). Under the influence of heterogeneous national strength and social system, initiating a support strategy for diversified entrepreneurs requires more insight into the determinants of self-employment in broader regions/communities (Khursheed et al., 2018). Focusing only on domestic entrepreneurial practice is more likely to induce disputes about equality of opportunity and hostile context (Huang \& Liu, 2019). Therefore, exploring perceptual enablers of the early-stage entrepreneurial activities in a cross-national theme is cleverly embedded in the practical needs of hospitable policy. This research question endows decision-makers to evaluate policy performance by analysing perceptual feedback from diversified entrepreneurs. Also, it helps develop novel institutional interventions to promote the targeted perception of individuals (natives versus newcomers).

In summary, the above-mentioned twofold value shed lights on the necessity of this article, which commits to reveal perceptual enablers of entrepreneurial activities in broader international society. This article employs and re-structures the cross-national data gathered by GEM to inform a pooled crosssectional dataset of entrepreneurial activities and corresponding perceptual factors. The aim is to explore 


\section{INTERNATIONAL JOURNAL OF ENTREPRENEURIAL KNOWLEDGE}

Issue 1, volume 9, ISSN 2336-2960 (Online)

www.ijek.org

the link between perceptual elements and early-stage entrepreneurial activities internationally (over 50 countries belonging to six continents except for Antarctica) from 2011 to 2019. The adopted sample has further expanded the evidential breadth of existing entrepreneurial perceptual related literature (e.g. Khursheed et al., 2018; Amini Sedeh et al., 2020) and deal with the gap in current empirical discourse to inform support policies and international evaluation criteria.

In addition, this empirical research updates the time span of the existing literature. Given that the entrepreneurial paradigm is highly dependent on the background of the times and international hotspots (Hsieh \& Wu, 2019), the latest time dimension also allows this research to fill the gap in theoretical timeliness. Grounded on emerging entrepreneurship scholarship, the revisit of the variables also symbolises decent theoretical value and practical significance of this article.

Regarding the structure of the article, it first proposes hypotheses of the possible determinants in crossnational conditions by investigating cutting-edge theoretical discourse. After integrating the data structure and research purpose, the corresponding methodology and statistical procedures are designed. According to the statistical approved equation, the predominant perceptual enablers can be identified. The empirical output and theoretical discussion are then intertwined with the extant literature and entrepreneurial practice, further unveiling the article's contributions.

\section{THEORETICAL BASES}

\subsection{Theoretical backgrounds}

Entrepreneurship literature fruitfully discusses the significance of entrepreneurial activities for economic revitalization and social development. Effective entrepreneurial activities can sustain economic growth (Dvorsky et al., 2019; Sergi et al., 2019), address social challenges such as labour market barriers faced by immigrants (Ram et al., 2017; Kloosterman \& Rath, 2018), and introduce emerging industries and corresponding innovation models (Abarca, 2018; Mohammadali \& Abdulkhaliq, 2019; Barrera Verdugo, 2020).

However, the entrepreneurial journey does not happen overnight. The literature that explores the prosperity of entrepreneurship has emerged in many branches, but most debates cannot be separated from the intricate interaction between individuals and entrepreneurial contexts. For instance, Bako et al. (2017) and Cera et al. (2020) examine the contribution of regional entrepreneurial resources/support to individual entrepreneurial intentions; some discussions mention relationship between education and professional experience, personality, and the regional entrepreneurial paradigm (e.g. Kumar et al., 2018; Renko et al., 2012); emergence of entrepreneurship ecosystem and incubator (Entezari, 2015; Suroso et al., 2020); the intertwinement between regional attributes and entrepreneurial propensity (Dvorsky et al ., 2019). Among these topics, the works about entrepreneurial intention emerge and bridge contextual factors and individual attributes, which inform individuals' heterogeneous attitudes towards entrepreneurship (e.g. Hussain \& Norashidah, 2015; Bako et al., 2017; Ojewumi \& Fagbenro, 2019).

Exogenous macro institutional characteristics (e.g. opportunity and institutional support, education, structural disadvantages) (Vidal-Suñé \& López-Panisello, 2013; Saeed et al., 2015; Ram et al., 2017) and endogenous individual traits (e.g. alertness, creativity) (Leutner et al., 2014; Karabulut, 2016) are two kernel categories of EI determinants. In recent years, emerging perceptual enablers have alluded to and delineated the interweaving between endogenous conditions and exogenous boosters.

For instance, social customs exacerbate entrepreneurs' fear of failure (Hessels et al., 2011), economic recession triggers public panic about entrepreneurial practice (Vodă et al., 2020), entrepreneurial education elevates self-efficacy (Mozahem \& Adlouni, 2021), individual capital and social economy jointly regulate entrepreneurs' accessibility of opportunities (Renko et al., 2012). In other words, the 


\section{INTERNATIONAL JOURNAL OF ENTREPRENEURIAL KNOWLEDGE}

Issue 1, volume 9, ISSN 2336-2960 (Online)

www.ijek.org

psychological/behavioural mapping of the entrepreneur's traits in the context constitutes perceptual elements.

Determinants of EI and EA are closely related, but the theoretical boundaries between the two are still bewildered (Van Gelderen et al., 2015). Transforming positive intentions into start-up entities inevitably has to face the test of multiple factors (Bogatyreva et al., 2019). The exclusivity/alienation faced by immigrant entrepreneurs is a typical example (Ram et al., 2017). What momentum is fueling entrepreneurial activities still have not reached a consensus between theoretical construction and policy practice (Rusu \& Roman, 2017). Therefore, to promote entrepreneurial literature's insights on economic prosperity, it is worth pondering how individuals interpret their situation (Gorgievski \& Stephan, 2016). Perceived factors reveal the hinders and advantages of the entrepreneur community, which conduce to decision-makers evaluate the interaction between entrepreneurs and formal institutions (e.g. Castaño et al., 2016). Factors including culture, technology, and institutionalisation also interfere with transforming potential entrepreneurs' aspirations into actions (Vendrell-Herrero et al., 2014; Morales et al., 2019; Matos \& Hall, 2020).

The significance of EA lies in the creation of economic value through practice. As mentioned above, the exploration of EA determinants has not formed a similar hierarchy to EI literature. Among the few perceptual investigation papers, most of the authors are dedicated to developing perceptual enablers in specific industries/economic regions. Terza (2020) explored the two perceptual dimensions of US entrepreneurial activity in the 2019 GEM data: perceived opportunity and perceived capability. Voda et al. (2020) adopted individual questionnaires from 18 countries in the EU in 2004 and 2017, which identified four factors: ability perception, opportunity recognition, networks, and fear of failure. Arafat et al. (2020) used cross-national data in 2013 to highlight that agricultural entrepreneurial activities are significantly boosted by opportunity identification and performed capability, but they refute the negative effect of 'fear of failure' (advocated by Gomes et al. al., 2020; Voda et al., 2020; Amini Sedeh et al., 2020).

In summary, in EA's empirical scholarship, the determinant of EA still mainly emanates from EI literature. However, most empirical studies on EA cannot verify the inclusiveness of the theory in the time dimension, industry dimension, and geographic dimension. This limits the understanding of advantageous perceptual factors in international debates and prevents policymakers from being aware of possible outdated trends and contextual outliers (e.g. financial crises and disasters). Therefore, in order to formulate related entrepreneurship support policies and further calibrate theories internationally, it is necessary to optimise and identify EA's perceptual enablers in an advanced time span and geographic scope.

\subsection{Theoretical underpins}

Perceived opportunity is a crucial factor that constructs people's aspiration and intention for selfemployement (Suroso et al., 2020). The term 'perceived opportunity' (PO) means the recognition of opportunities by potential entrepreneurs (Wasdani \& Mathew, 2014). The interweaving of personal traits and contextual dimensions constitutes the PO. For example, the opportunity structure that the society offered (Kloosterman \& Rath, 2018) and the individual's understanding of particular opportunities (Asante \& Affum-Ose, 2019). EI is positively affected by PO (Arab \& Sofiyabadi, 2013), that is, people who can more efficiently recognise market opportunities are more inclined to consider self-employment (Bohlmann et al., 2017). Adequate/decent entrepreneurial opportunities can generate intention and enthusiasm for potential entrepreneurs (Suroso et al., 2020). Compared to passive entrepreneurship (forced by livelihoods), opportunity-driven entrepreneurial activities are more intend to form growthoriented entities and embed in industrial trends (Angulo-Guerrero et al., 2017). Therefore, grasping the opportunity means that the specific needs of the market/economy are met, which might drive the public sector to provide the necessary support and convenience of entrepreneurial action (Entezari, 2015). In conclusion, adequate opportunities help not only potential entrepreneurs locate their business ideas in 


\section{INTERNATIONAL JOURNAL OF ENTREPRENEURIAL KNOWLEDGE}

Issue 1, volume 9, ISSN 2336-2960 (Online)

www.ijek.org

the appropriate market position but also make potential entrepreneurs attract social attention and public support.

Besides, individuals' entrepreneurial skills and knowledge are the pillars of game-changing selfemployment (De Massis et al., 2018). Entrepreneurial skills and knowledge are highly related to the competitiveness and performance of start-ups (Zainol et al., 2018). Therefore, entrepreneurial erudition and competence are essential for recognizing opportunities and overcoming the precarious early stage of entrepreneurship (Illés et al., 2015). Knowledge and skills are believed to inspire entrepreneurial intentions as well (Koe et al., 2012). The emergence of entrepreneurial education also echos the positive correlation between individual capability and entrepreneurial intentions (Hussain \& Norashidah, 2015). Catalysed by business skills and entrepreneurial knowledge, individuals also more intend to form expectations and aspirations for entrepreneurial activities (Galvão et al., 2018).

Moreover, fear of failure (FF) is a natural emotion/behaviour expression rooted in individual perceptions (Cacciotti et al., 2016), which could distorte rational thinking and bring risk for management practices (Frankovsky et al., 2015). Entrepreneurship activities let the 'pioneer' shoulder considerable responsibilities and risks (Santos et al., 2017). The aversion and fear of risk may cause individuals to be unable to make correct entrepreneurial decisions, thereby restricting the progression of entrepreneurial behaviour (Asiedu \& Nduro, 2015). However, just like other entrepreneurial perceptual factors, FF is a consequence of the interweaving of personal traits and context (Wennberg et al., 2013). Its feedback mechanism may vary with the personal response and macro institutions (e.g. Arafat et al., 2020), which could be a motivator or detrimentor theoretically (Cacciotti \& Hayton, 2015). Nevertheless, FF undoubtedly exerted an influence on entrepreneurs' decision-making, enterprising and entrepreneurial process. Its widespread impact on the broader entrepreneurial community still calls for empirical evidence.

According to extant debate, immersion in the entrepreneurial culture and social norm (CSN) also regulates the entrepreneurial process. The prosperity of entrepreneurial culture symbolises collective entrepreneurial norms and proactiveness consensus on entrepreneurship activities (Stuetzer et al., 2018). It may affect venture creation through multiple channels. For example, the perception of entrepreneurial culture can promote individual yearning and approbation of self-employment career (Kibler et al., 2014). Adequate CSN means that potential entrepreneurs are more inclined to perceive the value of entrepreneurial behaviour (ibid). CSN can also inspire better entrepreneurial outcomes (FernándezSerrano et al., 2018). In the process of transforming EI into EA, Bogatyreva et al. (2019) mentioned the possible influence of culture on the action that transforms entrepreneurial willingness into successful action. Although Bogatyreva et al. (2019) employed the essential national cultural characteristics proposed by Hofstede as variables instead of CSN, their conclusions also indicate that the discussion of cultural dimensions is highly promising. Morover, Obschonka (2017) called for more empirical data describing the value of CSN to tackle the dilemma of quantifying cultural dimensions of entrepreneurship.

\section{AIM AND METHODOLOGY}

In order to supplement the theoretical gap, provide diversified evidence for theoretical calibration, and inform the scholarship of entrepreneurial kinetics in the context of globalization, the purpose of this research is to locate and examine the prevailing perceptual elements that enable entrepreneurial activities within global scenarios. Based on above-mentioned theoretical underpins, the empirical hypotheses that could fulfill research purpose and supplement to extant knowledge are formulated as:

- H1: Individual's perception of entrepreneurial opportunities (PO) can promote their engagement in early-stage entrepreneurial activities. 


\section{INTERNATIONAL JOURNAL OF ENTREPRENEURIAL KNOWLEDGE}

Issue 1, volume 9, ISSN 2336-2960 (Online)

www.ijek.org

- H2: Individual's perception of their capabilities (PC) can promote corresponding engagement in early-stage entrepreneurial activities.

- H3: Individual's fear of failure (FF) can oppress their corresponding engagement in early-stage entrepreneurial activities

- H4: Individuals' immersion in a profound entrepreneurial culture and social norm can promote corresponding engagement in early-stage entrepreneurial activities.

\subsection{Sample and variables}

The study selected a broader empirical sample to calibrate possible perceptual determinants. The crossnational entrepreneurship data collected by Global Entrepreneurship Monitor (GEM) was employed and re-structured to construct a pooled cross-sectional database. Since all GEM data recruited in this study are open source, there are no additional interests and copyright conflicts that need to be disclosed.

The dataset covers 529 country-level observations from 2011 to 2019, and the annual average number of countries observed exceeds 50 . The data set has both time and country dimensions. However, due to the large fluctuations in the quantity of national data collected by GEM each year, it is served as pooled crosssectional data in this study rather than unbalanced panel data.

The dependent variable selected in this study is the Total early-stage Entrepreneurial Activity (TEA) rate. The measurement of TEA reflects the proportion of the individuals with entrepreneurial age (18-64 years old) that engage with entrepreneurial activity. According to the definition of GEM, entrepreneurs participating in early-stage entrepreneurial activities belong to the 'firm birth' stage, which includes nascent entrepreneurs who have established a business for less than three months and managers who have operated a start-up business for less than 3.5 years. The definition of TEA rate also effectively responds to the distinction between EI and EA in the theoretical concern.

Among the independent variables, PO, PC, FF, CSN were chosen.

The national 'Perceived opportunity rate' (PO) is meant to explain the proportion of the individuals (18-64 years old, exclude people who already are engaging in self-employment) who think they can perceive an adequate entrepreneurial opportunity; the national 'Perceived capitality rate' (PC) represents the proportion of the above group who believe they have the skills and knowledge necessary for entrepreneurship; 'Fear of failure' (FF) represents the proportion of the above group who regard the fear of failure as an obstacle to entrepreneurial behaviour; 'Culture and social norm' (CSN) reveals the strength and recognition level of entrepreneurial culture in the corresponding country.

\subsection{Description and regression model}

Since the sample data structure belongs to pooled cross-sectional data rather than panel data, it was modelled by pooled OLS regression. The statistical software employed for this method is STATA16. Given that the context/time dimension mentioned in the entrepreneur literature may have a trending connection with entrepreneurial activities, the potential joint impact of the time dimension in this pooled cross-sectional data cannot be ignored. Therefore, it is not possible to directly perform pooled OLS on this sample. First, dummy variables are set for the nine categories of year (2011-2019). The relationship between the time category and TEA rate is controlled by introducing dummy variables into pooled OLS, so as to ensure the stability and validity of the coefficients of the remaining variables in the time span. After setting up dummy variables and introducing the time dimension, the pooled OLS equation can be written as: 
INTERNATIONAL JOURNAL OF ENTREPRENEURIAL KNOWLEDGE

Issue 1, volume 9, ISSN 2336-2960 (Online)

www.ijek.org

$T E A=\beta \alpha_{0}+\beta_{1} F F+\beta_{2} C S N+\beta_{3} P C+\beta_{4} P O+\gamma_{i} \sum_{i=1}^{\lambda-1=8}$ yeari $+\varepsilon \quad$ (eight dummies match with nine categories of year, one ommitted)

Table 1 Descriptive statistics

\begin{tabular}{lrrrrr}
\hline Variable & Obs & Mean & Std. Dev. & Min & Max \\
\hline TEA & 529 & 12.823 & 7.716 & 2.1 & 41.46 \\
FF & 529 & 35.89 & 9.919 & 7.14 & 75.42 \\
CSN & 529 & 2.861 & .502 & 1.62 & 4.4 \\
PC & 529 & 51.034 & 14.891 & 9 & 89.48 \\
PO & 529 & 43.765 & 16.748 & 6.37 & 87.28 \\
\hline
\end{tabular}

Descriptive analysis is performed on the variables in the model (except dummies) as table1. The standard deviations of the five variables are all smaller than their corresponding statistical mean, and there is no serious data distortion problem can be identified. In addition, variables other than CSN have an extensive range of values, indicating that the degree of entrepreneurial activity and perceptual performance between countries showcase apparent heterogeneity.

Table 2 Pairwise correlations

\begin{tabular}{lrrrrr}
\hline Variables & $(1)$ & $(2)$ & $(3)$ & $(4)$ & $(5)$ \\
\hline (1) TEA & 1.000 & & & & \\
(2) FF & -0.382 & 1.000 & & & \\
& $(0.000)$ & & & & \\
(3) CSN & 0.220 & 0.002 & 1.000 & & \\
& $(0.000)$ & $(0.968)$ & & & \\
(4) PC & 0.720 & -0.417 & 0.119 & 1.000 & \\
& $(0.000)$ & $(0.000)$ & $(0.006)$ & & \\
(5) PO & 0.541 & -0.236 & 0.430 & 0.583 & 1.000 \\
& $(0.000)$ & $(0.000)$ & $(0.000)$ & $(0.000)$ & \\
\hline
\end{tabular}

In the pairwise correlations (table 2), the correlation between the five variables is confirmed. The independent variables and dependent variables have appropriate correlations and are statistically significant, the correlations between the independent variables are within a reasonable range, and there is no clear collinearity trend. Therefore, no feature refutes its linear assumption.

Table 3 First pooled OLS regression

\begin{tabular}{lrrrrrrrr}
\hline TEA & Coef. & St.Err. & t-value & p-value & {$[95 \%$ Conf } & Interval] & Sig & VIF \\
\hline FF & -.053 & .026 & -2.04 & .042 & -.104 & -.002 & $* *$ & 1.33 \\
CSN & 1.451 & .501 & 2.89 & .004 & .465 & 2.436 & $* * *$ & 1.28 \\
PC & .316 & .02 & 15.64 & 0 & .276 & .355 & $* * *$ & 1.82 \\
PO & .07 & .018 & 3.80 & 0 & .034 & .106 & $* * *$ & 1.92 \\
year1 & 2.414 & 1.075 & 2.25 & .025 & .302 & 4.526 & $* *$ & 1.97 \\
year2 & 3.339 & 1.005 & 3.32 & .001 & 1.364 & 5.314 & $* * *$ & 2.23 \\
year3 & 3.639 & .992 & 3.67 & 0 & 1.691 & 5.587 & $* * *$ & 2.26 \\
year4 & 3.212 & .993 & 3.24 & .001 & 1.261 & 5.163 & $* * *$ & 2.29 \\
year5 & 3.752 & 1.02 & 3.68 & 0 & 1.749 & 5.755 & $* * *$ & 2.09 \\
year6 & 2.906 & 1.004 & 2.89 & .004 & .933 & 4.879 & $* * *$ & 2.14 \\
year7 & 3.263 & 1.035 & 3.15 & .002 & 1.229 & 5.297 & $* * *$ & 1.99 \\
year8 & 3.107 & 1.06 & 2.93 & .004 & 1.025 & 5.189 & $* * *$ & 1.91
\end{tabular}


INTERNATIONAL JOURNAL OF ENTREPRENEURIAL KNOWLEDGE

Issue 1, volume 9, ISSN 2336-2960 (Online)

www.ijek.org

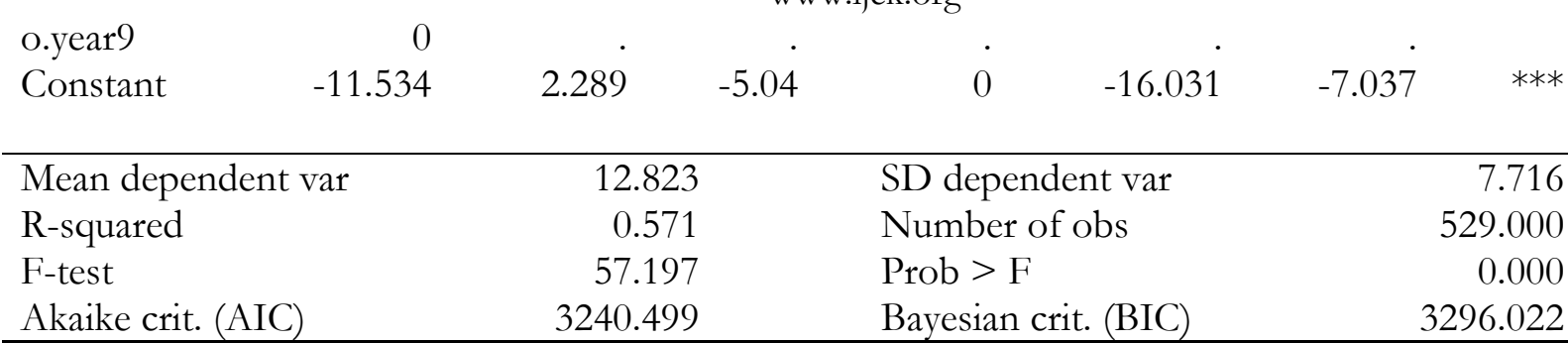

*** $p<.01, * * p<.05, * p<.1$

Variance inflation factor (VIF) and Breusch-Pagan / Cook-Weisberg test are employed for testing the multicollinearity and heteroscedasticity respectively.

Multicollinearity militated against the independence between independent variables, resulting in inflated standard errors of estimates (Thompson et al., 2017). The increase of VIF indicates a gradual deterioration of multicollinearity. VIF between 1-5 warrant no corrections but symbolise moderate correlation. A VIF greater than 5 indicates a multicollinearity issue worthy of corresponding corrective measures (Akinwande et al., 2015). Similarly, Breusch-Pagan / Cook-Weisberg is a crucial instrument for identify heteroscedasticity (Kaufman, 2013). Rejection of the null hypothesis in the BreuschPagan/Cook-Weisberg test implies the existence of heteroscedasticity.

Although the model shows no salient multicollinearity, when performing Breusch-Pagan / CookWeisberg to test the proposed pooled OLS equation, the Prob $>$ chi $2=0.0000$, which showcase heteroscedasticity. Therefore, to solve heteroscedasticity, the author performed a natural logarithmic transformation of the independent variable and the dependent variable in the model. The equation after transformation is:

$$
\ln T E A=\beta \alpha_{0}+\beta_{1} \ln f f+\beta_{2} \ln c s n+\beta_{3} \ln p c+\beta_{4} \ln p o+\gamma_{i} \sum_{i=1}^{8} \text { yeari }+\varepsilon
$$

\section{RESULTS}

After variable transformation, the Breusch-Pagan / Cook-Weisberg test for heteroskedasticity showed Prob $>$ chi2 $=0.5732$. The heteroscedasticity phenomenon no longer exists in this model. It can be known from the results of pooled OLS regression that when dummy variables are introduced to control the influence of the time dimension on variables, all four independent variables have a statistically significant effect on TEA rate (at the $95 \%$ confidence level). The specific relationship is: there is a negative effect of $\operatorname{lnff}$ on $\operatorname{lnTEA}$; lncsn, lnpo, and $\operatorname{lnpc}$ all have a promoting effect on $\ln$ TEA. The multicollinearity of the model was further examined. The VIF values of all variables are significantly less than 5 . Therefore, there is insufficient evidence to manefest multicollinearity.

Table 4 After log-transformation pooled OLS regression

\begin{tabular}{lrrrrrrrr}
\hline $\ln T E A$ & Coef. & St.Err. & t-value & p-value & {$[95 \%$ Conf } & Interval $]$ & Sig & VIF \\
\hline $\operatorname{lnff}$ & -.175 & .065 & -2.69 & .007 & -.303 & -.047 & $* * *$ & 1.320 \\
$\ln c s n$ & .522 & .113 & 4.61 & 0 & .3 & .745 & $* * *$ & 1.340 \\
$\ln p o$ & .154 & .055 & 2.82 & .005 & .047 & .261 & $* * *$ & 2.050 \\
$\ln$ pc & .93 & .072 & 12.87 & 0 & .788 & 1.072 & $* * *$ & 1.850 \\
year1 & .119 & .083 & 1.44 & .151 & -.044 & .282 & & 1.930 \\
year2 & .168 & .078 & 2.15 & .032 & .015 & .321 & $* *$ & 2.210 \\
year3 & .198 & .077 & 2.58 & .01 & .047 & .349 & $* *$ & 2.230
\end{tabular}


INTERNATIONAL JOURNAL OF ENTREPRENEURIAL KNOWLEDGE

Issue 1, volume 9, ISSN 2336-2960 (Online)

\begin{tabular}{|c|c|c|c|c|c|c|c|c|}
\hline \multicolumn{9}{|c|}{ www.ijek.org } \\
\hline year4 & .149 & .077 & 1.95 & .051 & -.001 & .3 & $*$ & 2.250 \\
\hline year5 & .189 & .079 & 2.41 & .016 & .035 & .344 & $* *$ & 2.050 \\
\hline year6 & .156 & .077 & 2.02 & .044 & .004 & .307 & $* *$ & 2.090 \\
\hline year7 & .175 & .08 & 2.20 & .029 & .018 & .332 & $* *$ & 1.950 \\
\hline year8 & .173 & .082 & 2.12 & .035 & .013 & .334 & $* *$ & 1.880 \\
\hline o.year9 & 0 & & & 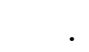 & & & & \\
\hline Constant & -1.863 & .425 & -4.38 & 0 & -2.698 & -1.027 & $* * *$ & \\
\hline Mean & dent var & & 2.392 & SD & dent var & & 0.560 & \\
\hline R-squ & & & 0.506 & $\mathrm{Nu}$ & of obs & & 529.000 & \\
\hline F-tes & & & 44.090 & Pro & & & 0.000 & \\
\hline Akail & AIC) & & 538.710 & Bay & crit. (BIC) & & 594.233 & \\
\hline
\end{tabular}

According to the results, the combination of the four independent variables can explain 50.6 percentage of the variance in $\ln T E A$. Combining this statistical output with the theoretical hypothesis can be obtained: As p-value $(\operatorname{lnpo})=0005<0.05$, the explanatory effect of lnpo (coefficient $=0.154)$ on $\ln$ TEA is statistically significant. The global prevalent positive influence of PO on entrepreneurial activity is illustrated. When PO increases by $1 \%$, the corresponding TEA will increase by $0.154 \%$. Hence, H1 is accepted, indicating that an individual's perception of entrepreneurial opportunities (PO) can promote their engagement in early-stage entrepreneurial activities. By analogy, $\ln p c$ ( $\mathrm{p}$-value $=0.000<0.05$; coefficient $=0.93$ ) and $\operatorname{lncs} n(\mathrm{p}$-value $=0.000<0.05$; coefficient $=0.522$ ) both has predominant positive effect on $\ln$ TEA. $\mathrm{H} 2$ and $\mathrm{H} 4$ are accepted, symbolising boost effects of perceived capability and entrepreneurial culture on global early-stage entrepreneurial activities. Conversely, lnff ( $p-$ value $=0.007<0.05$, coefficient $=-0.175$ is a significant negative predictor for $\ln T E A$. H3 is accepted, indicating the fear of failure opprese the early-stage entrepreneurial activities. When FF increases by $1 \%$, the corresponding TEA will decrease by $0.175 \%$.

Table 5 Model summary

\begin{tabular}{cccc}
\hline IV increase 1\% & Impact on DV & Coresponding hypothesis & $\begin{array}{c}\text { Expected } \\
\text { relationship }\end{array}$ \\
\hline PO & $0.154 \%$ & H1 confirmed & '+' positive \\
PC & $0.93 \%$ & H2 confirmed & '+' positive \\
FF & $-0.175 \%$ & H3 confirmed & '-' negative \\
CSN & $0.522 \%$ & H4 confirmed & '+' positive
\end{tabular}

Therefore, the model could be concluded as:

$$
\ln T E A=\beta \alpha_{0} \pm 0.175 \ln f f+0.522 \ln c s n+0.93 \ln p c+0.154 \ln p o+\gamma_{i} \sum_{i=2}^{8} \text { yeari }+\varepsilon
$$

\section{DISCUSSION}

This research explores cross-national data based on the controlled time dimension. It can be confirmed from the outcomes that the individual perceived opportunity and capability can promote individuals to carry out entrepreneurial activities. The advanced entrepreneurial culture and social norm that adults can immerse in also promote entrepreneurial action. On the contrary, entrepreneurs are more likely to avoid 


\section{INTERNATIONAL JOURNAL OF ENTREPRENEURIAL KNOWLEDGE}

Issue 1, volume 9, ISSN 2336-2960 (Online)

www.ijek.org

engaging with entrepreneurial behaviour due to fear of failure. Part of the results are in agreement with EI theories, and it also brings a new perspective in variable combinations.

First of all, the most powerful driving force for entrepreneurial activities in this study is entrepreneurs' perception of the skills/knowledge required for their entrepreneurship. This is in line with the expectations of Mozahem and Adlouni (2021) for skills training and entrepreneurial education. It supports the necessity of entrepreneurial skills for operating start-ups mentioned by De Massis et al. (2018) and Zainol et al. (2018). The discussion on PC is also consistent with empirical results in US data (Terza, 2020) and EU data (Voda, 2017). Regional consistency also means that in the six continents, how to promote the acquisition of entrepreneurial skills and knowledge will become a consensus to revitalize the regional entrepreneurial landscape. Following Illés et al. (2015) emphasised the value of entrepreneurs' competency, this article further sheds light on the catalysing effect of individuals' perception and selfevaluation of ability on transit from competency to proactive entrepreneurial activities.

This research also proves the entrepreneurial momentum brought about by the good opportunities perceived by the individual. In the broader context, most individuals are still driven by the contextual opportunity structure. This confirms Kloosterman and Rath's (2018) revisit for institutional support, who believe the structural disadvantage of opportunity still traps most individuals facing information asymmetry. In other words, although most countries may have various ways of creating market opportunities, the 'perceived opportunity' should serve as a criterion for evaluating entrepreneurial support/context. This insight also supports Entezari (2015) 's reflection on seizing opportunities to interact with institutions. More importantly, it extends Matos and Hall, (2020) 's discourse on institutional factors and provides a tracer for evaluating the effects of institutional changes in the transformation between intentions and EA.

In addition, this study also extends Bogatyreva et al.'s (2019) reflection on the relevance between entrepreneurial intention and entrepreneurial activities, proposing multiple pivoting premises for the transformation of entrepreneurial activities. The role of a new variable used to explain EA - the CSN, has been confirmed. As the value of entrepreneurship is elevated in the social norms and culture of the individual, entrepreneurial actions are motivated. This result first confirmed the cultural triggers of entrepreneurial activities proposed by Bogatyreva et al. (2019). As a concrete index, CSN further develops Hofstede factors used by Bogatyreva et al. (2019). In addition, this outcome also responds to Obschonka's (2017) appeal for quantifying the impact of entrepreneurial culture.

On the contrary, in addition to perceptual enablers, the research identified a perceptual hinder: the fear of failure. In EA literature, the fear of failure is affected by the time dimension and geographical dimension (e.g. turmoil, financial crisis, COVID-19), which leads to decision-makers unable to process their fear correctly. The results of this study confirm the interference of 'fear of failure' proposed by Santos et al. (2017), Asiedu and Nduro (2015) and Voda (2017) on entrepreneurial success/process, but partially refute that of Arafat et al. (2020). It means that entrepreneurs may not be able to take actions due to risks and pressures. This study also elaborated that FF serves as a hinder rather than a booster for individuals in most countries. Moreover, the study also confirmed that the timing impacted the country's overall entrepreneurial performance. In the case of controlling the influence of time, it confirmed the significant role of other variables.

In summary, this research responds to the research agenda identified in the past two years based on EA literature. For instance, Khursheed et al. (2018) call for involving longitudinal data, Arafat et al.'s (2020) expectations for cross-regional examination, and cultural variables that are encouraged to be introduced by Obschonka (2017) and Bogatyreva et al. (2019).

\section{CONCLUSIONS}




\section{INTERNATIONAL JOURNAL OF ENTREPRENEURIAL KNOWLEDGE}

Issue 1, volume 9, ISSN 2336-2960 (Online)

www.ijek.org

This study aims to investigate data from major entrepreneurial countries on six continents during 20112019 to examine possible perceptual enablers of nascent entrepreneurs further and calibrate the theoretical structure. The empirical data used in EA literature has thus realised the transformation from micro personal data (questionnaire) to cross-national data. As cultural factors have recently been considered relevant with entrepreneurial activities, this research innovatively introduced the entrepreneurial culture and social norm (CSN). The results confirmed that the three perceptual elements, including CSN, PC, and PO, are universal enablers for global nascent entrepreneurial activity. The fear of failure has proven to have a negative effect in most cases.

The research outcomes bring implication in both theoretical construct and policy-decision. First of all, the research progress of EI and EA is still in its infancy (Khursheed et al., 2018). For entrepreneurship discipline, data and methodological innovation are conducive to unveiling more EA enablers and the emerging policy debate. For example, the fear of failure has opposite effects in different data sets. In this study, the sample and methodology are updated while controlling the influence of the time dimension. The update of cross-national data means that the antecedents of the existing EI theory can be further verified in more complex EA contexts. Moreover, the connection between entrepreneurial journey and cultural factor has also gradually become prominent. This study selected appropriate indicators for quantifying entrepreneurial culture and confirmed the influence of culture on EA.

From a practical perspective, the positive effects of entrepreneurship on the economy are significant (Sergi et al., 2019). However, in the entrepreneurial literature of the 21 st century, diverse entrepreneurs are calling for inclusive theoretical attention (Ram et al., 2017). In response to the trend of migration and globalisation, entrepreneurship has become the ambition of many immigrants. Therefore, ignoring the diversity of entrepreneurial communities and focusing only on specific indigenous communities will neglect the cohorts that need motivation urgently. For instance, potential born global entrepreneurs, migrants, displaced people may face different hinders and opportunities. Therefore, this study proffers insights for decision-makers to evaluate the effectiveness of institutional context and entrepreneurial support. With the recognition of the perceptual enablers at the cross-national level (PC, PO, -FF, CSN), even if national conditions may vary and lead to differences in support strategies/entrepreneurship infrastructure, perceptual enablers can be used to design/assess related policies. The above implications will undoubtedly assist policy-makers delivery an inclusive environment to make entrepreneurship prosperous and serve as the cornerstone of international policy comparison.

This article also engages in academic dialogues about the practical process of entrepreneurial decisions. For potential budding entrepreneurs, the research also proffers insights into the transformation from blueprints to actions. After underlining the perceptual elements of global nascent entrepreneurs who genuinely carry out proactive entrepreneurial activities, these elements can guide confused and hesitant entrepreneurs to reflect and evaluate their perceptions and interactions with context. In other words, this conclusion provides a basis for monitoring the transit between intention and entrepreneurial activity, thereby facilitating self-assured decision-making of implementing entrepreneurial activities for potential entrepreneurs.

The hidden danger that still exists at this stage is that although this research reorganises and develops the GEM data set as much as possible, the valid cross-national panel data lacks (yearly surveyed countries are inconsistent ). With GEM's excellent work, this situation will be optimised. Hence, in the future, researchers shall use panel data to test and develop theories. In addition, researchers can also conduct cross-industry analysis to examine enablers or explore the validity of the research conclusions in extreme contexts (e.g. COVID-19).

\section{REFERENCES}




\section{INTERNATIONAL JOURNAL OF ENTREPRENEURIAL KNOWLEDGE}

Issue 1, volume 9, ISSN 2336-2960 (Online)

www.ijek.org

Abarca, J. E. O. (2018). The cultural entrepreneur: constitution, organization and ways of operating. International Journal of Entrepreneurial Knowledge, 6(1), 5-15.

Acs, Z. J., Estrin, S., Mickiewicz, T., \& Szerb, L. (2018). Entrepreneurship, institutional economics, and economic growth: an ecosystem perspective. Small Business Economics, 51(2), 501-514.

Akinwande, M.O., Dikko, H.G. \& Samson, A. (2015). Variance inflation factor: as a condition for the inclusion of suppressor variable (s) in regression analysis. Open Journal of Statistics, 5(7), 754-767

Amini Sedeh, A., Beck, J., \& Forghani Bajestani, M. (2020). Perceptual versus institutional determinants of entrepreneurial entry. Journal of Small Business and Enterprise Development, 27(2), 329-346.

Angulo-Guerrero, M.J., Pérez-Moreno, S., \& Abad-Guerrero, I.M. (2017). How economic freedom affects opportunity and necessity entrepreneurship in the OECD countries. Journal of Business Research, 73, 30-37.

Arab, Z., \& Sofiyabadi, J. (2013). Entrepreneurship indicators with an emphasis on Global Entrepreneurship Monitor. International Journal of Recent Research and Applied Studies, 16(2), 288-296.

Arafat, M. Y., Saleem, I., Dwivedi, A. K., \& Khan, A. (2020). Determinants of agricultural entrepreneurship: a GEM data based study. International Entrepreneurship and Management Journal, 16(1), 345-370.

Asante, E. A., \& Affum-Osei, E. (2019). Entrepreneurship as a career choice: The impact of locus of control on aspiring entrepreneurs' opportunity recognition. Journal of Business Research, 98, 227-235.

Asiedu, M., \& Nduro, K. (2015). Polytechnic students' entrepreneurial knowledge, preferences and perceived barriers to start-up business. European Journal of Business and Management, 7(21), 20-28.

Barberis, E., \& Solano, G. (2018). Mixed embeddedness and migrant entrepreneurship: hints on past and future directions. An Introduction. Sociologica, 12(2), 1-22.

Barrera Verdugo, G. (2020). Relationship between innovation and sustainability in Latin American countries: Differences by perceptual characteristics of early-stage entrepreneurs. Cogent Business \& Management, 7(1), https://doi.org/10.1080/23311975.2020.1831766.

Bako, Y.A., Ajibode, I.A., Oluseye, A.B. \& Aladelusi, K.B. (2017). An Investigation of Entrepreneurial Intention among Entrepreneurship Students In South-West Nigeria Polytechnics. International Journal of Entrepreneurial Knowledge, 5(2), 16-32.

Bogatyreva, K., Edelman, L. F., Manolova, T. S., Osiyevskyy, O., \& Shirokova, G. (2019). When do entrepreneurial intentions lead to actions? The role of national culture. Journal of Business Research, 96, 309-321.

Bohlmann, C., Rauch, A., \& Zacher, H. (2017). A lifespan perspective on entrepreneurship: Perceived opportunities and skills explain the negative association between age and entrepreneurial activity. Frontiers in psychology, 8, https://doi.org/10.3389/fpsyg.2017.02015.

Brás, G.R. (2020). Determinants of entrepreneurship in Latvia and Baltic countries in general: an empirical approach. European Journal of International Management, 14(5), 817-841.

Cacciotti, G., \& Hayton, J. C. (2015). Fear and entrepreneurship: A review and research agenda. International Journal of Management Reviews, 17(2), 165-190.

Cacciotti, G., Hayton, J. C., Mitchell, J. R., \& Giazitzoglu, A. (2016). A reconceptualization of fear of failure in entrepreneurship. Journal of Business Venturing, 31(3), 302-325.

Castaño, M. S., Méndez, M. T., \& Galindo, M. Á. (2016). The effect of public policies on entrepreneurial activity and economic growth. Journal of Business Research, 69(11), 5280-5285.

Cera, G., Mlouk, A., Cera, E., \& Shumeli, A. (2020). The Impact of Entrepreneurship Education on Entrepreneurial Intention. A Quasi-Experimental Research Design. Journal of Competitiveness, 12(1), 39- 56.

De Massis, A., Kotlar, J., Wright, M., \& Kellermanns, F. W. (2018). Sector-Based Entrepreneurial Capabilities and the Promise of Sector Studies in Entrepreneurship. Entrepreneurship Theory and Practice, 42(1), 3-23.

Dileo, I., \& Losurdo, F. (2016). Investigating Socio-Economic and Perceptual Variables of Early-Stage Entrepreneurial Activity in Selected EU Countries. Olsztyn Economic Journal, 11(4), 317-330. 


\section{INTERNATIONAL JOURNAL OF ENTREPRENEURIAL KNOWLEDGE}

Issue 1, volume 9, ISSN 2336-2960 (Online)

www.ijek.org

Dvorsky, J., Mikelova, L., Petrakova, Z., \& Rózsa, Z. (2019). Impact of social attributes on the propensity for entrepreneurship among university students. Journal of International Studies, 12(1), 253-268

Entezari, Y. (2015). Building knowledge-based entrepreneurship ecosystems: Case of Iran. Procedia-social and behavioral sciences, 195, 1206-1215.

Fernandes, C., Ferreira, J.J., Raposo, M., Sanchez, J., \& Hernandez-Sanchez, B. (2020). Determinants of entrepreneurial intentions: an international cross-border study, International Journal of Innovation Science, 10(2), 129-142.

Fernández-Serrano, J., Berbegal, V., Velasco, F., \& Expósito, A. (2018). Efficient entrepreneurial culture: a cross-country analysis of developed countries. International Entrepreneurship and Management Journal, 14(1), 105-127.

Frankovsky, M., Birknerova, Z., \& Zbihlejova, L. (2015). Possibilities of identification of predictors of occurrence of cognitive distortions in managerial work. Polish Journal of Management Studies, 12(2): 69-78.

Galvão, A., Ferreira, J.J., \& Marques, C. (2018). Entrepreneurship education and training as facilitators of regional development: A systematic literature review. Journal of Small Business and Enterprise Development, 25(1), 17-40.

Gomes, C., Braga, V., \& Correia, A. (2020). The Impact of Perceptual Variables and Country-Level Culture on Nascent Entrepreneurship. In De Nisco, A. (Ed.) European Conference on Innovation and Entrepreneurship (pp. 261-269). Academic Conferences International Limited, Reading.

Gorgievski, M.J., \& Stephan, U. (2016). Advancing the psychology of entrepreneurship: A review of the psychological literature and an introduction. Applied Psychology, 65(3), 437-468.

Hessels, J., Grilo, I., Thurik, R., \& van der Zwan, P. (2011). Entrepreneurial exit and entrepreneurial engagement. Journal of Evolutionary Economics, 21(3), 447-471.

Hsieh, Y. J., \& Wu, Y. J. (2019). Entrepreneurship through the platform strategy in the digital era: Insights and research opportunities. Computers in Human Behavior, 95, 315-323.

Huang, X., \& Liu, C. Y. (2019). Immigrant entrepreneurship and economic development: a local policy perspective. Journal of the American Planning Association, 85(4), 564-584.

Hussain, A., \& Norashidah, D. (2015). Impact of entrepreneurial education on entrepreneurial intentions of Pakistani Students. Journal of Entrepreneurship and Business Innovation, 2(1), 43-53.

Illés, B.C., Dunay, A. \& Jelonek, D. (2015). The entrepreneurship in Poland and in Hungary: future entrepreneurs education perspective. Polish Journal of Management Studies, 12(1), 48-58.

Karabulut, A. T. (2016). Personality traits on entrepreneurial intention. Procedia-Social and Behavioral Sciences, $229,12-21$.

Kaufman, R. L. (2013). Heteroskedasticity in regression: Detection and correction. Sage Publications, New York.

Khursheed, A., Mustafa, F., Fatima, M., \& Siddique, F. (2018). Entrepreneurial Intentions: Gem Based Empirical Analysis On The Northern Europe And Asian Countries. International Journal of Entrepreneurial Knowledge, 6 (2), 59-70.

Kibler, E., Kautonen, T., \& Fink, M. (2014). Regional social legitimacy of entrepreneurship: Implications for entrepreneurial intention and start-up behaviour. Regional Studies, 48(6), 995-1015.

Kloosterman, R.C. \& Rath, J. (2018). Mixed embeddedness revisited: a conclusion to the symposium. Sociologica, 12(2), 103-114.

Koe, W. L., Sa'ari, J. R., Majid, I. A., \& Ismail, K. (2012). Determinants of entrepreneurial intention among millennial generation. Procedia-Social and Behavioral Sciences, 40, 197-208.

Kumar, N., Al Mamun, A., Ibrahim, M. D. \& Yusoff, M. N. H. (2018). Entrepreneurial orientation and antecedents of low-income household heads in Kelantan, Malaysia. Journal of International Studies, 11(1), 140-151.

Leutner, F., Ahmetoglu, G., Akhtar, R., \& Chamorro-Premuzic, T. (2014). The relationship between the entrepreneurial personality and the Big Five personality traits. Personality and individual differences, 63, 58-63. 


\section{INTERNATIONAL JOURNAL OF ENTREPRENEURIAL KNOWLEDGE}

Issue 1, volume 9, ISSN 2336-2960 (Online)

www.ijek.org

Matos, S., \& Hall, J. (2020). An exploratory study of entrepreneurs in impoverished communities: when institutional factors and individual characteristics result in non-productive entrepreneurship. Entrepreneurship \& Regional Development, 32(1-2), 134-155.

Mohammadali, Z. M., \& Abdulkhaliq S. S. (2019). Prospects and Challenges of Entrepreneurship Development in the Kurdistan Region of Iraq: An Overview. International Journal of Entrepreneurial Knowledge, 7(2), 4-16.

Morales, C., Holtschlag, C., Masuda, A. D., \& Marquina, P. (2019). In which cultural contexts do individual values explain entrepreneurship? An integrative values framework using Schwartz's theories. International Small Business Journal, 37(3), 241-267.

Morozova, I. A., Popkova, E. G., \& Litvinova, T. N. (2019). Sustainable development of global entrepreneurship: infrastructure and perspectives. International Entrepreneurship and Management Journal, 15(2), 589-597.

Mozahem, N. A., \& Adlouni, R. O. (2021). Using Entrepreneurial Self-Efficacy as an Indirect Measure of Entrepreneurial Education. The International Journal of Management Education, 19(1), https://doi.org/10.1016/j.ijme.2020.100385

Munir, H., Jianfeng, C. \& Ramzan, S. (2019). Personality traits and theory of planned behavior comparison of entrepreneurial intentions between an emerging economy and a developing country. International Journal of Entrepreneurial Behavior \& Research, 25(3), 554-580.

Obschonka, M. (2017). The quest for the entrepreneurial culture: psychological big data in entrepreneurship research. Current Opinion in Bebavioral Sciences, 18, 69-74.

Ojewumi, K. A., \& Fagbenro, D. A. (2019). Entrepreneurial Intention Among Polytechnic Students In Nigeria: The Role Of Self-Efficacy And Social Networks. International Journal of Entrepreneurial Knowledge, 7(1), 20-30.

Ojiaku, O. C., Nkamnebe, A. D., \& Nwaizugbo, I. C. (2018). Determinants of entrepreneurial intentions among young graduates: perspectives of push-pull-mooring model. Journal of Global Entrepreneurship Research, 8(1), 1-17.

Ram, M., Jones, T., \& Villares-Varela, M. (2017). Migrant entrepreneurship: Reflections on research and practice. International Small Business Journal, 35(1), 3-18.

Renko, M., Shrader, R.C. \& Simon, M. (2012). Perception of entrepreneurial opportunity: a general framework. Management Decision, 50 (7), 1233-1251.

Rusu, V.D. and Roman, A., 2017. Entrepreneurial activity in the EU: An empirical evaluation of its determinants. Sustainability, 9(10), https://doi.org/10.3390/su9101679.

Saeed, S., Yousafzai, S. Y., Yani-De-Soriano, M., \& Muffatto, M. (2015). The role of perceived university support in the formation of students' entrepreneurial intention. Journal of small business management, 53(4), 1127-1145.

Santos, S. C., Caetano, A., Spagnoli, P., Costa, S. F., \& Neumeyer, X. (2017). Predictors of entrepreneurial activity before and during the European economic crisis. International Entrepreneurship and Management Journal, 13(4), 1263-1288.

Sergi, B. S., Popkova, E. G., Bogoviz, A. V., \& Ragulina, J. V. (2019). Entrepreneurship and economic growth: the experience of developed and developing countries. In Sergi, B. S., \& Scanlon, C. C. (Eds.), Entrepreneurship and Development in the 21st Century (pp.3-32). Emerald publishing limited, Bingley.

Stuetzer, M., Audretsch, D.B., Obschonka, M., Gosling, S.D., Rentfrow, P.J., \& Potter, J. (2018). Entrepreneurship culture, knowledge spillovers and the growth of regions. Regional Studies, 52(5), 608-618.

Suroso, A., Rafinda, A., \& Gal, T. (2020). The Evaluation Of Entrepreneur Incubation Program At Higher Education. International Journal of Entrepreneurial Knowledge, 8(2), 14-26.

Terza, C. G. (2020). Economic Trends And Entrepreneurial Activity. New Trends in Sustainable Business and Consumption, 4-6, 503-509. 


\section{INTERNATIONAL JOURNAL OF ENTREPRENEURIAL KNOWLEDGE}

Issue 1, volume 9, ISSN 2336-2960 (Online)

www.ijek.org

Thompson, C.G., Kim, R.S., Aloe, A.M., \& Becker, B.J. (2017). Extracting the variance inflation factor and other multicollinearity diagnostics from typical regression results. Basic and Applied Social Psychology, 39(2), 81-90.

Tunali, C. B., \& Sener, S. (2019). The determinants of entrepreneurship in Turkey. Procedia Computer Science, $158,648-652$.

Van Gelderen, M., Kautonen, T., \& Fink, M. (2015). From entrepreneurial intentions to actions: Selfcontrol and action-related doubt, fear, and aversion. Journal of Business Venturing, 30(5), 655-673.

Vendrell-Herrero, F., González-Pernía, J. L., \& Peña-Legazkue, I. (2014). Do incentives matter to promote high technology-driven entrepreneurial activity?. International Entrepreneurship and Management Journal, 10(1), 43-66.

Vidal-Suñé, A., \& López-Panisello, M. B. (2013). Institutional and economic determinants of the perception of opportunities and entrepreneurial intention. Investigaciones Regionales-Journal of Regional Research, (26), 75-96.

Vodă, A. I., Butnaru, G. I., \& Butnaru, R. C. (2020). Enablers of entrepreneurial activity across the European Union-An analysis using GEM individual data. Sustainability, 12(3), https://doi.org/10.3390/su12031022.

Wannamakok, W., \& Chang, Y.Y. (2020). Understanding nascent women entrepreneurs: an exploratory investigation into their entrepreneurial intentions. Gender in Management, 35(6), 553-566.

Wasdani, K. P., \& Mathew, M. (2014). Potential for opportunity recognition along the stages of entrepreneurship. Journal of global entrepreneurship research, 4(1), 1-24.

Wennberg, K., Pathak, S., \& Autio, E. (2013). How culture moulds the effects of self-efficacy and fear of failure on entrepreneurship. Entrepreneurship \& Regional Development, 25(9-10), 756-780.

Zainol, N.R., Al Mamun, A., Ahmad, G.B., \& Simpong, D.B. (2018). Human Capital and Entrepreneurial Ompetencies towards Performance of Informal Microenterprises in Kelantan, Malaysia. Economics \& Sociology, 11(4), 31-50.

\section{BRIEF DESCRIPTION OF AUTHOR:}

\section{Shuai Qin}

ORCID ID: https://orcid.org/0000-0002-3532-414X

PhD Researcher

Affiliation: Aston Business School, Centre for Research in Ethnic Minority Entrepreneurship, Aston University, Birmingham, UK, B4 7DA

Email:190229083@aston.ac.uk

Web page: https://www.aston.ac.uk/research/bss/abs/centres-hubs/creme

Area of interest: entrepreneurship, ethnic minority entrepreneurship, refugee entrepreneurship, small business management 